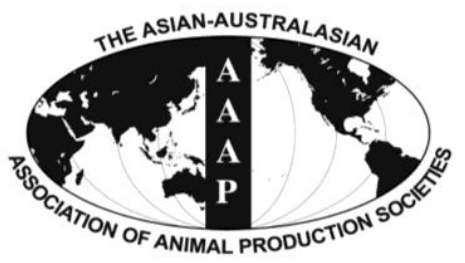

Asian-Aust. J. Anim. Sci.

Vol. 25, No. 11 : 1553-1558 November 2012

http://dx.doi.org/10.5713/ajas.2012.12254

www.ajas.info

pISSN 1011-2367 elSSN 1976-5517

\title{
Effects of Stocking Density or Group Size on Intake, Growth, and Meat Quality of Hanwoo Steers (Bos taurus coreanae)
}

\author{
Sang Moo Lee, Jae Yeon Kim and Eun Joong Kim* \\ Department of Animal Science and Biotechnology, Kyungpook National University, Sangju 742-711, Korea
}

\begin{abstract}
This study was conducted to investigate the effects of stocking density or group size on feed intake, daily gain, and carcass characteristics of Hanwoo (Korean indigenous breed) steers reared from 7 months to 31 months of age. Thirty Hanwoo steers were divided into four groups with three replicates each (a total of 12 pens). In each group, one (G1), two (G2), three (G3), and four steers (G4) per pen were allocated as treatments. Pen size was $32.0 \mathrm{~m}^{2}$, and therefore Hanwoo steers in G1, G2, G3, and G4 were reared under different space allowances, i.e. 32.0, 16.0, 10.6, and $8.0 \mathrm{~m}^{2} / \mathrm{steer}$, respectively. Steers were reared following a conventional beef cattle management method in Korea, and were offered a fixed amount of commercial concentrate with ad libitum forages. Results were subjected to analysis of variance with stocking density as the main effect, and significance was declared at $p<0.05$. Although total feed intake was not significantly altered, it numerically increased in animals of low stocking density (G1) compared to those subjected to high stocking density treatment (i.e. G4). Feed conversion ratio was higher ( $\mathrm{p}<0.05)$ in G3 compared to G1 and G2. Animals in G1 (low stocking density) grew faster ( $\mathrm{p}<0.05)$ than those of high stocking density (G3 and G4). Back fat thickness, meat yield index, and meat yield grade were similar among all levels of stocking density. However, longissimus muscle area was larger in G1 and G2 (p<0.01) compared to G3 and G4, and animals in G3 produced smaller carcasses ( $\mathrm{p}<0.05)$. Carcass quality traits, including marbling score, meat color, fat color, texture, maturity and meat quality grade, as determined by a group of experts, were not significantly different among the treatments. In conclusion, lower stocking density resulted in increased feed efficiency, daily gain, and carcass weight in Hanwoo steers. However it remains unclear whether such differences are the results of stocking density or group size, or a combination of both. Nonetheless, these results confirm previous studies reporting a negative effect of increased stocking density on animal productivity. Further, animal welfare under an intensive farming system in relation to economical return is discussed. (Key Words: Stocking Density, Hanwoo, Growth, Meat Quality, Animal Welfare)
\end{abstract}

\section{INTRODUCTION}

In many Asian countries, including South Korea where animal production is largely intensified, stocking density and group size are seldom considered since such factors are generally determined by the farmer or manager and depend on current farming conditions, including animal housing, management, financing capability, and animal prices, etc. However, recent interest in the development of a highquality, environmentally-friendly animal production system combined with animal welfare concerns has provoked controversy regarding stocking areas and animal densities in intensive farming systems. Animals such as cattle are very sociable, and their social behaviors are known to be heavily influenced by stocking density since there are

\footnotetext{
* Corresponding Author: Eun Joong Kim. Tel: +82-54-530-1228, Fax: +82-54-530-1229, E-mail: ejkim2011@knu.ac.kr Submitted May 10, 2012; Accepted Jun. 24, 2012; Revised Sept. 14, 2012
}

complex rankings among animals in a group (Friend and Polan, 1974; Kondo et al., 1984; Rind and Phillips, 1999; Boe and Færevik, 2003). In calves especially, aggressive behaviors such as threatening, attacking, and fighting increase with higher stocking density (Kondo et al., 1989), and these behaviors are known to result in reduced animal production (Boe and Færevik, 2003). Under conditions of high stocking density, it has been reported that there are several factors that hinder animal welfare. For example, unfavorable fluctuations in temperature and moisture, air pollution, and increased amounts of feces and urine are known to increase animal stress, which in turn leads to slower growth rates due to rapid degradation of nutrients (Dantzer and Morméde, 1983; Mitchell et al., 1988). Gehlbach et al. (1966) reported that stocking density greatly impacts disease occurrence and daily gain. In terms of eating behavior in relation to stocking density, Watts et al. (2000) reported that feed intake increases with high stocking density due to competition between animals. In 
another study by Li et al. (2010), animals stocked at a higher group size but at the same space per head showed better growth rates with reduced back fat thickness at an earlier fattening period (15 to 18 months), whereas at a late fattening period (30 months), carcass weight and carcass quality appeared to remain the same. However, there is still very little information available on animal performance and meat quality, especially in an Asian cattle breed such as Hanwoo, a Korean indigenous breed. In this study, we investigated the effects of stocking density or group size on animal performance, meat production, and quality. Our discussion further extends to high quality beef production in the context of animal welfare.

\section{MATERIALS AND METHODS}

Experimental design, animals and feeding management

The experiment was conducted on 30 Hanwoo steers (7

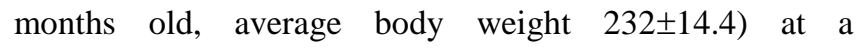
commercial farm located in Chilgok, Gyeongbuk Province, Korea $\left(36.03272^{\circ}, 128.363792^{\circ}\right)$ over a 25 -month period. Animals were allocated in a pen with a size of $32 \mathrm{~m}^{2}(4 \times 8$ $\mathrm{m}$ ), and stocking densities were 1, 2, 3 and 4 animals per pen (namely G1, G2, G3, and G4, respectively) as experimental treatments, each conducted in triplicate (Table 1). Feeding regimes were divided into three phases, namely growing period (7 to 14 months), early fattening period (15 to 22 months), and late fattening period (22 to 31 months) which mimic a typical feeding management standard for beef cattle in Korea. During the growing period, animals were offered $4 \mathrm{~kg}$ of commercial concentrates, $0.5 \mathrm{~kg}$ of alfalfa hay, and $1.2 \mathrm{~kg}$ of timothy per day as basal diets (all in DM basis), and tall fescue hay was offered ad libitum. During the early fattening period, $7.7 \mathrm{~kg} \mathrm{DM} / \mathrm{d}$ of concentrates was offered with free access to rice straw. Likewise for the late fattening period, $7.7 \mathrm{~kg} \mathrm{DM} / \mathrm{d}$ of concentrates was offered, but with $0.8 \mathrm{~kg} \mathrm{DM} / \mathrm{d}$ of rice straw. The concentrates used were formulated for beef cattle growers and commercially obtained from Nonghyup Feed Company, Ltd. (Seoul, Korea). The diets offered were divided into two meals fed at 7 am and 6 pm during the day, except for the ad libitum forages. Feed bins for concentrates and forages were located on opposite sides so that animals

Table 1. Animal allocation and experimental design of the study

\begin{tabular}{lcccc}
\hline \multirow{2}{*}{ Items } & \multicolumn{4}{c}{ Treatments } \\
\cline { 2 - 5 } & $\mathrm{G} 1$ & $\mathrm{G} 2$ & $\mathrm{G} 3$ & $\mathrm{G} 4$ \\
\hline Pen sizes & $4 \times 8 \mathrm{~m}$ & $4 \times 8 \mathrm{~m}$ & $4 \times 8 \mathrm{~m}$ & $4 \times 8 \mathrm{~m}$ \\
Number of & 1 & 2 & 3 & 4 \\
$\quad$ animals per pen & & & & \\
Area per animal & $32.0 \mathrm{~m}^{2}$ & $16.0 \mathrm{~m}^{2}$ & $10.6 \mathrm{~m}^{2}$ & $8.0 \mathrm{~m}^{2}$ \\
Number of replication & 3 & 3 & 3 & 3 \\
Total number of animals & 3 & 6 & 9 & 12 \\
\hline
\end{tabular}

were less competitive. Vitamin and mineral supplements were included in the commercial concentrates, and animals had free access at all times to supplementary mineral blocks and fresh water in a water cup. Chemical compositions of experimental diets are presented in Table 2 and 3.

\section{Measurements}

Dry matter intake was measured based on the difference between the amounts of feed offered and refused. Feed refusals were collected the next day and weighed for determination of feed intake. Since an individual feeding facility was not available at this commercial farm, the total amount of feed consumed per group was measured in triplicate, and feed intake was calculated based on the number of animals within each group. Body weights were measured individually at the beginning of the experiment, after a 3-month interval, and then at the end of the study. At the end of the experiment, animals were transported to a nearby commercial slaughterhouse where they were

Table 2. Chemical composition (\%) and feed ingredients (\%) of concentrates used in this experiment (dry matter basis unless otherwise stated)

\begin{tabular}{|c|c|c|c|}
\hline Item & Growing & $\begin{array}{c}\text { Early } \\
\text { fattening }\end{array}$ & $\begin{array}{c}\text { Late } \\
\text { fattening }\end{array}$ \\
\hline \multicolumn{4}{|l|}{ Chemical composition } \\
\hline Crude protein & 15.97 & 14.83 & 13.10 \\
\hline Ether extract & 3.87 & 4.20 & 5.58 \\
\hline Crude fiber & 9.15 & 7.62 & 8.60 \\
\hline Crude ash & 8.42 & 6.67 & 6.78 \\
\hline Nitrogen free extract & 62.59 & 66.50 & 66.31 \\
\hline Calcium & 1.39 & 0.91 & 0.92 \\
\hline Phosphorus & 0.56 & 0.46 & 0.40 \\
\hline Neutral detergent fiber & 33.87 & 30.91 & 28.76 \\
\hline Acid detergent fiber & 16.36 & 13.74 & 13.79 \\
\hline Total digestible nutrients & 78.27 & 81.89 & 82.74 \\
\hline \multicolumn{4}{|l|}{ Ingredients } \\
\hline Corn grain & 24.0 & 25.5 & 30.0 \\
\hline Wheat grain & 8.5 & 18.0 & 16.5 \\
\hline Soybean meal & 3.0 & 6.0 & 5.0 \\
\hline Wheat bran & 9.0 & 5.0 & 10.0 \\
\hline Corn gluten feed & 11.5 & 16.0 & 15.0 \\
\hline Rapeseed meal & 7.0 & - & - \\
\hline Cane molasses & 4.0 & 3.5 & 3.5 \\
\hline Coconut meal & 14.0 & 9.5 & - \\
\hline Cottonseed hull pellet & - & - & 4.0 \\
\hline Palm meal & 15.0 & 13.0 & 10.0 \\
\hline Distillers grain & - & - & 2.5 \\
\hline Salt dehydrated & 0.5 & 0.6 & 0.6 \\
\hline Limestone & 2.5 & 1.7 & 1.5 \\
\hline Vitamin premix & 0.1 & 0.1 & 0.1 \\
\hline Mineral premix & 0.1 & 0.1 & 0.1 \\
\hline Others & 0.8 & 1.0 & 1.2 \\
\hline Total & 100.0 & 100.0 & 100.0 \\
\hline
\end{tabular}


Table 3. Chemical composition of forages used in this experiment (dry matter basis unless otherwise stated)

\begin{tabular}{lcccc}
\hline Item & Alfalfa & Timothy & Tall fescue & Rice straw \\
\hline Organic matter (\%) & 91.0 & 93.0 & 93.8 & 88.4 \\
Crude protein (\%) & 18.8 & 14.6 & 9.9 & 4.0 \\
Ether extract (\%) & 3.14 & 4.94 & 3.31 & 1.61 \\
Crude fiber (\%) & 36.1 & 29.3 & 31.7 & 43.2 \\
Nitrogen free extract (\%) & 32.9 & 44.2 & 48.0 & 39.6 \\
Neutral detergent fiber (\%) & 49.9 & 66.3 & 63.2 & 74.8 \\
\hline
\end{tabular}

slaughtered according to a commercial procedure. Carcasses were stored in hanging position for $24 \mathrm{~h}$ at $0^{\circ} \mathrm{C}$. Using the Korean standard carcass grading system, a carcass grader determined carcass characteristics and meat quality, including carcass weight, back fat thickness, size of longissimus dorsi, marbling score, meat color, fat color, meat texture and meat maturity.

\section{Calculation and statistical analysis}

Feed conversion ratio was calculated by dividing total feed intake $(\mathrm{kg} / \mathrm{d})$ by daily body weight gain $(\mathrm{kg} / \mathrm{d})$. To determine treatment differences over the entire experimental growth period, all data were subjected to analysis of variance using statistical analysis system software (SAS, release ver. 9.1 (2000)) according to the General Linear Model procedure. Further comparison of means was conducted using Duncan's multiple range test. Statistical significance was declared if $\mathrm{p}<0.05$.

\section{RESULTS AND DISCUSSION}

\section{Animal performance}

The purpose of this study was to examine the effects of stocking density on animal performance and meat quality in Hanwoo steers. The experimental design was based on a commercial feeding management procedure under typical farming conditions in Asia. Unfortunately, however, the current experimental design was unable to determine whether the effects originated from stocking density or group size, or a combination of both. Hence, the results and discussion mostly focus on the effects of stocking density within the experimental design.

Throughout the experiment, a large portion (i.e. concentrates) of the diet consumed by the steers was restricted, and differences among the treatments were minimal. Therefore, feed intake results were not subjected to statistical analysis but instead are presented as mean values with standard errors. In addition, for dry matter intake measurement, the whole fattening period was divided into three periods, namely growing (7 to 14 months), early fattening (15 to 22 months), and late fattening (23 to 30 months) periods, according to a typical and commercial fattening program of Hanwoo steers. Total feed intake, including concentrates and forages, was $9.6 \mathrm{~kg} \mathrm{DM} / \mathrm{d}$ across all treatments, and this value was somewhat comparable with typical feed intakes of this breed in the literature (Lee et al., 2010; Park et al., 2011). Differences in feed intake were marginally notable in the early fattening period. For example, intake of concentrates was restricted to $7.7 \mathrm{~kg}$ $\mathrm{DM} / \mathrm{d}$ across all treatment groups. However, intake of rice straw offered ad libitum was numerically higher in G1, in which a single animal was allocated in a pen, compared to the rest of the treatments. Our results were in agreement with Gonyou and Sticklin (1998), who reported reduced feed intake with increased stocking density and group size in swine. On the other hand, Nielsen et al. (1995) observed no difference in feed intake with increased group size in swine when space allowance per animal was kept constant. Similarly, McConnell et al. (1987) reported that feed intake and feed conversion efficiency during pig production are not compromised as long as enough space is available during ad libitum intake. However, others have reported that if space per animal or feed supply is limited or reduced, then feed intake and production are negatively affected $(\mathrm{Li}$ et al., 2010). Overall feed conversion ratio was greater $(\mathrm{p}<0.05)$ in G1 and G2 compared to G3 and G4 (Table 4), which suggests that animals in $\mathrm{G} 1$ or $\mathrm{G} 2$ required less feed in order to gain the same body weight relative to G3. It is hypothesized that such a difference was due to a reduction in stress mediated by decreased competition for food and space within the designated space allowance. Indeed, animals grown alone with more allowed space consume more feed than those reared in groups (Gonyou et al., 1992; de Haer and de Vries, 1993).

Effects of stocking density on body weight gain are presented in Table 4. Specifically, animals in G1 gained $(\mathrm{p}<0.05)$ more body weight compared to the other treatments. It is interesting to note that although a large proportion of feed intake was restricted, variation among the animals was quite large, resulting in significant differences in daily gain. Despite continuous efforts to improve animal breeding, there are still many issues related to feed efficiency that are responsible for such variations among animals.

Gehlbach et al. (1966) reported that the number of animals per group affects performance of swine regardless of floor type, especially in the warm season. In a study by Yamada et al. (2003) in pigs, there were no significant 
Table 4. Effect of stocking density on feed intake, daily gain, and feed conversion ratio (dry matter basis unless otherwise stated)

\begin{tabular}{|c|c|c|c|c|}
\hline \multirow{2}{*}{ Item } & \multicolumn{4}{|c|}{ Treatments } \\
\hline & G1 & G2 & G3 & G4 \\
\hline \multicolumn{5}{|l|}{ Growing period } \\
\hline Concentrates $(\mathrm{kg} / \mathrm{d})$ & $4.0 \pm 0.00$ & $4.0 \pm 0.00$ & $4.0 \pm 0.00$ & $4.0 \pm 0.00$ \\
\hline Alfalfa & $0.5 \pm 0.00$ & $0.5 \pm 0.00$ & $0.5 \pm 0.00$ & $0.5 \pm 0.00$ \\
\hline Timothy & $1.2 \pm 0.00$ & $1.2 \pm 0.00$ & $1.2 \pm 0.00$ & $1.2 \pm 0.00$ \\
\hline Tall fescue & $2.4 \pm 0.42$ & $2.1 \pm 0.10$ & $2.3 \pm 0.15$ & $2.2 \pm 0.18$ \\
\hline Total intake (kg/d) & $8.1 \pm 0.42$ & $7.8 \pm 0.10$ & $8.0 \pm 0.15$ & $7.9 \pm 0.18$ \\
\hline \multicolumn{5}{|l|}{ Early fattening period } \\
\hline Concentrates (kg/d) & $7.7 \pm 0.00$ & $7.7 \pm 0.00$ & $7.7 \pm 0.00$ & $7.7 \pm 0.00$ \\
\hline Rice straw (kg/d) & $4.6 \pm 1.07$ & $3.8 \pm 0.26$ & $3.5 \pm 0.24$ & $3.4 \pm 0.22$ \\
\hline Total intake $(\mathrm{kg} / \mathrm{d})$ & $12.6 \pm 1.07$ & $11.5 \pm 0.26$ & $11.2 \pm 0.24$ & $11.1 \pm 0.22$ \\
\hline \multicolumn{5}{|l|}{ Late fattening period } \\
\hline Concentrates $(\mathrm{kg} / \mathrm{d})$ & $8.7 \pm 0.11$ & $8.3 \pm 0.36$ & $8.3 \pm 0.31$ & $8.1 \pm 0.10$ \\
\hline Rice straw (kg/d) & $0.8 \pm 0.00$ & $0.8 \pm 0.00$ & $0.8 \pm 0.00$ & $0.8 \pm 0.00$ \\
\hline Total intake (kg/d) & $9.5 \pm 0.11$ & $9.1 \pm 0.36$ & $9.1 \pm 0.31$ & $8.9 \pm 0.10$ \\
\hline \multicolumn{5}{|l|}{ Daily gain } \\
\hline Initial BW (kg) & $247 \pm 15.5^{\mathrm{ns}}$ & $210 \pm 14.7$ & $238 \pm 15.0$ & $231 \pm 12.3$ \\
\hline Final BW (kg) & $809 \pm 24.8^{\mathrm{ns}}$ & $7,338 \pm 14.6$ & $730 \pm 68.3$ & $733 \pm 10.6$ \\
\hline BW gain (kg) & $561 \pm 21.7^{\mathrm{ns}}$ & $522 \pm 17.4$ & $492 \pm 65.3$ & $502 \pm 14.0$ \\
\hline Daily gain (kg/d) & $0.76 \pm 0.03^{\mathrm{a}}$ & $0.71 \pm 0.03^{\mathrm{ab}}$ & $0.67 \pm 0.04^{\mathrm{b}}$ & $0.68 \pm 0.02^{\mathrm{b}}$ \\
\hline Feed conversion ratio $(\mathrm{kg} / \mathrm{kg})$ & $13.2 \pm 0.18^{\mathrm{b}}$ & $13.3 \pm 0.23^{\mathrm{b}}$ & $14.1 \pm 0.50^{\mathrm{a}}$ & $13.7 \pm 0.16^{\mathrm{ab}}$ \\
\hline
\end{tabular}

ns $=$ Not significant. ${ }^{\mathrm{a}, \mathrm{b}}$ Means in a row with different superscripts are significantly different $(\mathrm{p}<0.05)$.

differences in body weight gain or feed conversion efficiency between pigs separated into low density and standard density groups. In this study, although not statistically proven, feed intake may have had an impact on daily gain. More importantly, it can be speculated that environmental stress on steers was reduced when stocking density was changed from $8.0 \mathrm{~m}^{2}$ to $32 \mathrm{~m}^{2}$ per steer, which was in agreement with others (Kondo et al., 1989; González et al., 2008; Li et al., 2010). Although we did not investigate daily gain according to growth stage, early fattening period (15 to 22 months) was affected by stocking density when animals were in linear growth phase (data not shown). Indeed, another study (Li et al., 2010) showed that Hanwoo steers grow much faster during early fattening period as opposed to late fattening period when grouped differently. It is thought that animals are far more active during rapid growth phase, whereas their growth rate slows down when they approach their maximum body weight. As a result, animal behavior becomes much calmer and is affected very little in terms of body weight gain relative to active growth period. On the other hand, in a study by Lee et al. (2007) that investigated the relationships between various factors for the prevention of calf diarrheal disease, a high number of calves per area was shown to be directly related with high incidence of diarrheal disease.

\section{Carcass characteristics and meat quality}

Carcass weight (Table 5) was much heavier $(\mathrm{p}<0.05)$ in steers reared with a larger space allowance compared to the other treatments, possibly due to increased daily gain (Table 4). Such differences in carcass weight were reflected in the longissimus dorsi (LD) muscle area. Specifically, animals in G1 and G2 had larger sized LD muscles than animals in G3 and G4 ( $<$ 0.05). Results from our study were in agreement with Gehlbach et al. (1996), who observed that a larger area per animal has positive effects on animal growth and feed efficiency, which in turn results in heavier carcass weight. Back fat thickness was not significantly different among the treatments, with an average of $14.0 \mathrm{~mm}$ (Table 5). There are few studies that have investigated back fat thickness with regards to stocking density, but in a study by Li et al. (2010), back fat thickness did not differ among Hanwoo steers regardless of stocking density. The LD muscle area in our study was smaller in $\mathrm{G} 3\left(91 \mathrm{~cm}^{2}\right)$ animals and bigger in $\mathrm{G} 2$ $\left(104 \mathrm{~cm}^{2} ; \mathrm{p}<0.05\right)$ ones, which was in agreement with previous reports on this indigenous breed. For example, Hanwoo steers subjected to concentrates-based feeding that were slaughtered at 26 and 28 months demonstrated LD muscle areas of 87 to 90 and 89 to $94 \mathrm{~cm}^{2}$, respectively (Cho et al., 2009). Similarly, Jeong et al. (2010) reported an LD muscle area of 86 to $91 \mathrm{~cm}^{2}$ in Hanwoo steers fed different levels of crude protein and total digestible nutrients. Further, meat yield index and yield grade were not different $(p>0.05)$ across the treatments. In terms of meat quality traits, including marbling score, meat color, fat color, texture, maturity, and meat quality grade, were 
Table 5. Effects of stocking density on carcass characteristics and meat quality

\begin{tabular}{|c|c|c|c|c|}
\hline \multirow{2}{*}{ Item } & \multicolumn{4}{|c|}{ Treatments } \\
\hline & G1 & G2 & G3 & G4 \\
\hline Carcass weight (kg) & $459 \pm 10.5^{\mathrm{a}}$ & $425 \pm 8.5^{\mathrm{ab}}$ & $407 \pm 33.7^{\mathrm{b}}$ & $424 \pm 9.0^{\mathrm{ab}}$ \\
\hline \multicolumn{5}{|l|}{ Quantity traits } \\
\hline Back fat thickness (mm) & $15 \pm 1.2^{\mathrm{ns}}$ & $14 \pm 0.3$ & $13 \pm 1.9$ & $13 \pm 1.1$ \\
\hline Longissimus muscle area $\left(\mathrm{cm}^{2}\right)$ & $99 \pm 5.1^{\mathrm{ab}}$ & $104 \pm 4.4^{\mathrm{a}}$ & $91 \pm 0.5^{\mathrm{c}}$ & $93 \pm 2.7^{\mathrm{bc}}$ \\
\hline Meat yield index & $63.7 \pm 0.8^{\mathrm{ns}}$ & $66.2 \pm 0.6$ & $64.4 \pm 1.4$ & $65.0 \pm 1.9$ \\
\hline Yield grade $(\mathrm{A}, \mathrm{B}, \mathrm{C})^{1}$ & $1.7 \pm 0.58^{\mathrm{ns}}$ & $2.3 \pm 0.29$ & $2.0 \pm 0.34$ & $2.3 \pm 0.25$ \\
\hline \multicolumn{5}{|l|}{ Quality traits } \\
\hline Marbling score ${ }^{2}$ & $4.3 \pm 2.08^{\mathrm{ns}}$ & $5.2 \pm 0.29$ & $4.1 \pm 1.68$ & $3.6 \pm 0.75$ \\
\hline Meat color ${ }^{3}$ & $5.0 \pm 0.00^{\mathrm{ns}}$ & $4.8 \pm 0.29$ & $5.1 \pm 0.19$ & $4.7 \pm 0.14$ \\
\hline Fat color ${ }^{4}$ & $3.0 \pm 0.00^{\mathrm{ns}}$ & $3.0 \pm 0.00$ & $3.0 \pm 0.00$ & $3.0 \pm 0.00$ \\
\hline Texture $^{5}$ & $1.3 \pm 0.58^{\mathrm{ns}}$ & $1.2 \pm 0.29$ & $1.3 \pm 0.58$ & $1.4 \pm 0.14$ \\
\hline Maturity $^{6}$ & $2.3 \pm 0.58^{\mathrm{ns}}$ & $2.5 \pm 0.00$ & $2.0 \pm 0.00$ & $2.0 \pm 0.00$ \\
\hline Meat quality grade ${ }^{7}$ & $3.0 \pm 0.00^{\mathrm{ns}}$ & $3.3 \pm 0.29$ & $2.8 \pm 0.84$ & $2.8 \pm 0.25$ \\
\hline
\end{tabular}

${ }^{1} \mathrm{~A}=3, \mathrm{~B}=2, \mathrm{C}=1 .{ }^{2} 1$ devoid, $9=$ abundant. ${ }^{3} 1=$ white, $7=$ yellow. ${ }^{4} 1=$ dark red, $7=$ bright. ${ }^{5} 1=$ good, $3=$ bad.

${ }^{6} 1=$ fine, $3=$ coarse ${ }^{7} 1++$ grade $=5,1+$ grade $=4,1$ st grade $=3,2$ nd grade $=2,3$ rd grade $=1$.

$\mathrm{ns}=$ Not significant. ${ }^{\mathrm{a}, \mathrm{b}}$ Means in a row with different superscripts are significantly different $(\mathrm{p}<0.05)$.

similar across the treatments.

\section{IMPLICATIONS}

Results of this study demonstrate that animals in larger allowed spaces consumed more feed, grew faster, and produced larger carcasses, resulting in the production of economically valuable meat. However, it remains unclear whether such discrepancies can be attributed to the effect of stocking density or group size or a combination of both, due to the complex experimental design. As indicated earlier, the experimental design of this study is often adopted since the selected pen size and animal number are representative of typical farming conditions in Asia, especially Korea. Nonetheless, improved farming practices (i.e. larger space allowance per animal) are likely to be welcomed by animal welfare groups while meeting growing consumer demand for animal products produced by environmentally-friendly methods and according to animal welfare regulations. Indeed, producers and farmers in many Asian countries now face growing demand from customers to follow environmentally-friendly production methods while reducing production costs. Further studies are needed to identify the optimum group size and area per animal without compromising growth rate and production. This is very important to ensure a sustainable animal industry as well as animal welfare to fulfill both animals and humans.

\section{REFERENCES}

Boe, K. E. and G. Færevik. 2003. Grouping and social preferences in calves, heifers and cows. Appl. Anim. Behav. Sci. 80:175190.
Cho, Y. M., S. S. Chang, H. C. Kim, T. I. Kim, B. K. Park, B. H. Paek, J. H. Kim and E. G. Kwon. 2009. Effects of concentrate feeding method and slaughter age on growth performance, feed intake and carcass characteristics of Hanwoo steers. J. Anim. Sci. Technol. (Korean) 51:53-60.

Dantzer, R. and P. Mormède. 1983. Stress in farm animals: a need for reevaluation. J. Anim. Sci. 57:6-18.

de Haer, L. C. M. and A. G. de Vries. 1993. Feed intake patterns of and feed digestibility in growing pigs housed individually or in groups. Livest. Prod. Sci. 33:277-292.

Friend, T. H. and C. E. Polan. 1974. Social rank, feeding behavior, and free stall utilization by dairy cattle. J. Dairy Sci. 57:12141220.

Gehlbach, G. D., D. E. Becker, J. L. Cox, B. G. Harmon and A. H. Jensen. 1966. Effects of floor space allowance and number per group on performance of growing-finishing swine. J. Anim. Sci. 25:386-391.

Gonyou, H. W., R. P. Chapple and G. R. Frank. 1992. Productivity, time budgets and social aspects of eating in pigs penned in groups of five or individually. Appl. Anim. Behav. Sci. 34:291301.

Gonyou, H. W. and W. R. Stricklin. 1998. Effects of floor area allowance and group size on the productivity of growing/finishing pigs. J. Anim. Sci. 76:1326-1330.

González, L. A., A. Ferret, X. Manteca, J. L. Ruíz-de-la-Torre, S. Calsamiglia, M. Devant and A. Bach. 2008. Effect of the number of concentrate feeding places per pen on performance, behavior, and welfare indicators of Friesian calves during the first month after arrival at the feedlot. J. Anim. Sci. 86:419-431.

Jeong, J., N. I. Seong, I. K. Hwang, S. B. Lee, M. S. Yu, I. S. Nam and M. I. Lee. 2010. Effects of level of CP and TDN in the concentrate supplement on growth performances and carcass characteristics in Hanwoo steers during final fattening period. J. Anim. Sci. Technol. (Korean) 52:305-312.

Kondo, S., N. Kawakami, H. Kohama and S. Nishino. 1984. Changes in activity, spatial pattern and social behavior in calves after grouping. Appl. Anim. Ethol. 11:217-228. 
Kondo, S., J. Sekine, M. Okubo and Y. Asahida. 1989. The effect of group size and space allowance on the agonistic and spacing behavior of cattle. Appl. Anim. Behav. Sci. 24:127-135.

Lee, S., Y. Kim, Y. Oh and W. Kwak. 2010. Effects of feeding methods of total mixed ration on behavior patterns of growing Hanwoo steers. Asian-Aust. J. Anim. Sci. 23:1469-1475.

Lee, Y.-L., H.-R. Lee, J.-B. Ahn, J.-Y. Song, J.-J. Jang and M.-J. Lee. 2007. A Study of the correlation between breeding density and the azimuth of cattle sheds affected calf diarrhea disease. Kor. J. Vet. Ser. 30:133-144.

Li, S. G., Y. X. Yang, Y. J. Rhee, W. J. Jang, J. J. Ha, S. K. Lee and Y. H. Song. 2010. Growth, behavior, and carcass traits of fattening Hanwoo (Korean Native Cattle) steers managed in different group sizes. Asian-Aust. J. Anim. Sci. 23:952-959.

McConnell, J. C., J. C. Eargle and R. C. Waldorf. 1987. Effects of weaning weight, co-mingling, group size and room temperature on pig performance. J. Anim. Sci. 65:1201-1206.

Mitchell, G., J. Hattingh and M. Ganhao. 1988. Stress in cattle assessed after handling, after transport and after slaughter. Vet. Rec. 123:201-205.
Nielsen, B. L., A. B. Lawrence and C. T. Whittemore. 1995. Effect of group size on feeding behaviour, social behaviour, and performance of growing pigs using single-space feeders. Livest. Prod. Sci. 44:73-85.

Park, B. K., N. J. Choi, S. M. Lee, H. C. Kim, B. S. Jeon, M. J. Kim, Y. K. Oh, S. K. Im, S. K. Hong, J. S. Chang, I. H. Hwang, Y. J. Kim and E. G. Kwon. 2011. Effects of dietary multinutritional targeted supplementation according to different growth stages on performance and carcass characteristics of Hanwoo steers. Asian-Aust. J. Anim. Sci. 24:222-229.

Rind, M. I. and C. J. C. Phillips. 1999. The effects of group size on the ingestive and social behaviour of grazing dairy cows. Anim. Sci. 68:589-596.

SAS. 2000. User's guide:Statistics, release. 8.1 version Edition. SAS Inst., Cary, NC. USA.

Watts, J. M. and J. M. Stookey. 2000. Vocal behaviour in cattle: the animal's commentary on its biological processes and welfare. Appl. Anim. Behav. Sci. 67:15-33.

Yamada, M., Y. Watabe, A. Sato, K. Yamada and H. Kanno. 2003. Effect of different population density on the growth, carcass characteristics, and fatty acid composition of lipid and muscle tissue in pigs. Jap. J. Swine Sci. 40:65-72. 